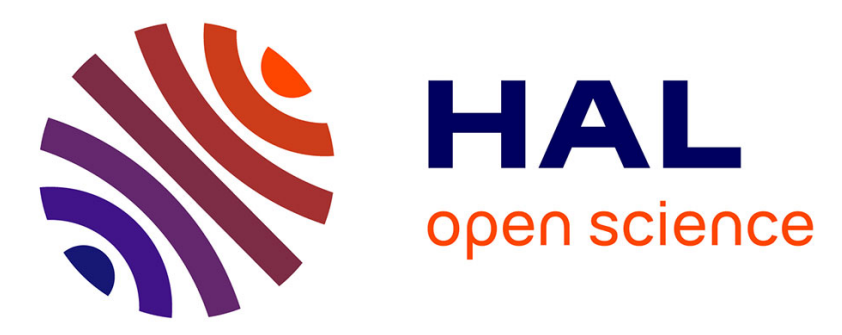

\title{
Practices during the active second stage of labor: A survey of French midwives
}

Chloé Barasinski, Anne Debost-Legrand, Didier Lémery, Françoise Vendittelli

\section{To cite this version:}

Chloé Barasinski, Anne Debost-Legrand, Didier Lémery, Françoise Vendittelli. Practices during the active second stage of labor: A survey of French midwives. Midwifery, 2018, 60, pp.48 - 55 . 10.1016/j.midw.2018.02.001 . hal-01893518

\section{HAL Id: hal-01893518 https://hal.science/hal-01893518}

Submitted on 16 Nov 2018

HAL is a multi-disciplinary open access archive for the deposit and dissemination of scientific research documents, whether they are published or not. The documents may come from teaching and research institutions in France or abroad, or from public or private research centers.
L'archive ouverte pluridisciplinaire HAL, est destinée au dépôt et à la diffusion de documents scientifiques de niveau recherche, publiés ou non, émanant des établissements d'enseignement et de recherche français ou étrangers, des laboratoires publics ou privés. 
Practices during the active second stage of labor: a survey of French midwives

Chloé Barasinski, RM, MPH ${ }^{\mathrm{a}}$, Anne Debost-Legrand, MD, MPH ${ }^{\mathrm{a}, \mathrm{b}}$, Didier Lemery, MD, PhD, Professor ${ }^{\mathrm{a}, \mathrm{b}, \mathrm{c}}$, Françoise Vendittelli, MD, PhD ${ }^{\mathrm{a}, \mathrm{b}, \mathrm{c}}$

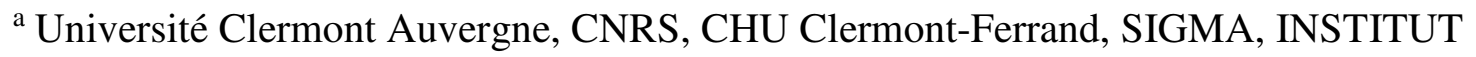
PASCAL, F-63000 Clermont-Ferrand, France;

${ }^{\mathrm{b}}$ Réseau de Santé en Périnatalité d'Auvergne, F-63000 Clermont-Ferrand, France;

${ }^{\mathrm{C}}$ AUDIPOG (Association des Utilisateurs de Dossiers Informatisés en Pédiatrie, Obstétrique; et Gynécologie), RTH Laennec Medical University, 7 rue Guillaume Paradin, 69372 Lyon Cedex 08, France.

Corresponding author: Chloé Barasinski, Centre Hospitalier Universitaire de ClermontFerrand, Hôpital Estaing, Pôle Femme et Enfant, Recherche Clinique en Périnatalité, 1 place Lucie et Raymond Aubrac, 63003 Clermont-Ferrand Cedex 1, FRANCE. Tel: (33) 047375 50 89, e-mail: cbarasinski@chu-clermontferrand.fr

\footnotetext{
Abstract

Objective: The principal objective of our study was to describe the practices reported by French midwives during the active second stage of labor (expulsion phase).

Design: This cross-sectional Internet survey questioned French midwives who attended at least one delivery in 2013.
} 
Setting: This open survey was posted on a website from June 15 through December 1, 2014.

Participants: 1496 midwives from 377 maternity units participated in the study.

Measurements and findings: The midwives most often reported suggesting horizontal positions during the active second stage (supine with footholds, lithotomy, lithotomy with knees turned in, or lateral positions). Non-horizontal positions were more often proposed by midwives in level I units $(p<0.0001)$. Almost half the midwives responding $(46.4 \%)$, especially those working in level III units $(51.1 \%, p=0.006)$, advised Valsalva pushing. The mean maximum pushing time was $35.3 \mathrm{~min} \pm 12.8 \mathrm{~min}$. Nearly all the midwives favored the "hands on" technique at delivery (91.4\%), and 24\% reported using warm compresses on the perineum at delivery.

Key conclusion: Most midwives advised horizontal positions for delivery. The practices of French midwives differed as a function of where they worked. The midwives, especially those in level III facilities, reported that they cannot always ensure "physiological childbirth".

Implications for practice: The practices of French midwives must become more evidencebased. The development of professional guidelines for midwives in France appears essential. This study also helps to prioritize national training for midwives.

Keywords: delivery position; manual perineal support; midwifery practice; perineal massage; pushing second stage; second stage of labor

\section{Abbreviations}

CNGOF: National College of French Gynecologists and Obstetricians 
CNSF: National College of French Midwives

DRESS: Bureau of research, studies, evaluation and statistics (Direction de la Recherche, des études et de l'évaluation et des statistiques)

NICE: National Institute for Health and Care Excellence

OASIS: Obstetric Anal Sphincter InjurieS

RCM: Royal College of Midwives

SAE: Annual Health Facility Statistics (Statistique Annuelle des Etablissements de santé) 


\section{Introduction}

France has the highest birthrate in Europe, with around 800,000 babies born each year (Bellamy and Beaumel, 2016). Childbirth is a frequent event and nearly all (99.1\%) of deliveries occur in hospitals (INSEE, 2014). In 2013, there were 519 maternity units nationwide (DRESS). Around half of the births (47\%) took place in maternity units with 500 to 1999 deliveries a year, $41 \%$ in those with at least 2000 deliveries a year and $2.5 \%$ in facilities with fewer than 500 deliveries per year (Court of Auditors : Cour des Comptes, 2014). France is one of the European countries where women use epidural analgesia most often. In 2012, for example, $75.0 \%$ of women in spontaneous labor had epidurals (Audipog). A midwife is routinely assigned to support each parturient, in all hospitals, public or private. Most births result from non-operative vaginal deliveries (66.9\%), accompanied most often by a midwife (79.7\%) (Blondel and Kermarrec, 2011).

During the expulsive phase, midwives can advise one or several positions, choose to direct (or coach) the pushing or not, and use different techniques for perineal protection. The positions used during delivery remain controversial (Gupta et al., 2012; Kibuka et al., 2017). Vertical positions, for example, are often said to reduce the risk of aortocaval compression, improve acid-base outcomes in newborns, enable stronger and more efficient uterine contractions, and facilitate fetal progression through the effects of gravity and improved pelvic alignment (Gupta et al., 2012). Nonetheless, some vertical positions may create an excess risk of severe perineal lacerations (Elvander et al., 2015), which increase the volume of postpartum blood loss and thus the risk of an immediate postpartum hemorrhage (de Jonge et al., 2007;

Vendittelli, 2012). An Australian study compared 9 maternal positions for delivery and found the semi-recumbent position most closely associated with perineal tears or lacerations (OR 1.16, 95\% CI 1.01-1.33) (Soong et al., 2005). In another study, the lithotomy, compared with the sitting, position was found to be associated more often than other positions with obstetric 
anal sphincter injuries (OASIS) in nulliparous (aRR 1.17, 95\% CI 1.06-1.29) and parous women (aRR 1.66, 95\% CI 1.35-2.05) (Elvander et al., 2015). At the same time, there are different techniques that midwives can use to reduce these tears and lacerations. The metaanalysis by Aasheim et al. (2011) concluded that the use of warm compresses during expulsion appear to reduce severe perineal lacerations significantly as does perineal massage during delivery, compared with the "hands-off" technique. Moreover, although hands-off appears to reduce episiotomy rates (Aasheim et al., 2011), the development of a "hands-on" policy in several departments reduced the number of OASIS (Hals et al., 2010; Laine et al., 2012), and a meta-analysis of cohort studies also found that hands-on had a strong protective effect against OASIS (Bulchandani et al., 2015). Thus numerous experts strongly recommend the use of perineal support/hands-on at delivery (Ismail et al., 2015). The type of pushing used at delivery may also affect both the maternal perineum and fetal well-being (Barasinski et al., 2016). The meta-analysis by Lemos et al. (2017) confirmed the absence of scientific evidence for preferring one pushing technique over another.

There are no French guidelines for physiological childbirth, except for the first set of guidelines issued by the French National College of midwives (CNSF) about oxytocin augmentation (Dupont et al., 2017). Moreover, although studies have examined midwives practices during the intrapartum period (Hanson, 1998; RCM, 2010), no nationwide survey in France has reported these practices here. Our research hypothesis is that the practices of French midwives differ in some ways from those of their colleagues in other developed countries.

The principal objective of our study was to describe the practices reported by French midwives during the active second stage of labor. Our secondary objective was to assess whether these practices differ according to midwives' experience or the level of the maternity ward where they work (as defined below). 


\section{Methods}

\section{Design}

We conducted a cross-sectional Internet survey of French midwives, both hospital-based and in private practice, who perform deliveries in equipped facilities (i.e., not home births). In our convenience sample, only midwives who attended at least one delivery in 2013 were eligible. The midwives participating in this study were informed on the survey home page of the time required to complete the survey, their right to withdraw from the study (via a personal number obtained at the end of the study), and the study's objectives. No identifying information was collected. The relevant ethics committee approved this study on March 31, 2014 (CECIC Rhône-Alpes-Auvergne, Grenoble, IRB 00005921).

Development and pretesting of the questionnaire (Supplementary file 1).

The questionnaire covered the different practices known to be used in France, during all three stages of delivery. It was pilot tested by 10 midwives practicing in maternity wards of different levels (I, II, and III), different sizes $(<500, \geq 500-\leq 1500$, and $>1500$ births/year), and different statuses (public or private). Level I units have no neonatology department, while level II units have a department of neonatology in the same building as or in immediate proximity to the delivery suite, and level III units have, in addition to a neonatology unit, a neonatal intensive care in the same building as or in immediate proximity to the delivery room. Accordingly, the higher the hospital level, the more likely it is to deal with high-risk and complicated pregnancies. The online version was tested on different brands of computers and different versions of browser software.

\section{Recruitment process}


This open survey was posted on a website from June 15 through December 1, 2014. Midwives were recruited for the survey through the e-mail lists and websites of the national council of midwives and the national college of French midwives. A single reminder e-mail was sent.

\section{Survey administration}

The website was exclusively devoted to the survey, and the midwives had direct access to its information page. No incentives were offered for participation in this voluntary survey. Once the midwife agreed to complete the questionnaire, the first question was whether she had attended a delivery in 2013 (the inclusion criterion). If the response was negative, the survey ended.

The survey comprised 46 closed questions, 35 of which are used in this study (Supplementary File 1). Six questions specifically concerned position, six pushing methods, 8 perineal protection and support techniques, and 3 placental delivery. For the part about birthing positions, 8 different positions were proposed to the midwives, each illustrated by a photograph. We chose these positions from the earlier practice surveys (Hanson, 1998; RCM, 2010) and included several versions of the supine position. The questions were organized according to the chronology of the delivery, with no randomization of item order. We used some adaptive questions to streamline the questionnaire when possible. The items about practices during expulsion were distributed onto 4 separate screens (positions, pushing methods, perineal protection, and perineal support techniques). Practices for the third stage of labor were on another page. The questionnaire ended with five questions to assess the midwives' feelings about facilitating physiological childbirth. All items were mandatory and if one was not completed, the respondent could not go on the next screen. Participants could change their answers throughout the survey via the table of contents to the left of the questionnaire. Because many midwives responded from their workplace, and therefore several 
midwives used the same computer, software controls to prevent multiple entries from the same individuals could not be used.

\section{Analysis}

Only completed questionnaires were analyzed; there was no time limit for their completion. Our principal outcome was the prevalence of the practices midwives reported. The responses are reported as percentages of all respondents. They were subsequently compared according to maternity unit level and according to the midwives' experience (years of practice) $(\leq 5 ; 6$ 15; > 15). The Chi2 test (or Fisher's exact test, as appropriate) was used to compare the qualitative variables, and Student's T test for the quantitative variables. The threshold of significance was set at $p<0.05$. The statistical analyses were performed with SAS software (version 9.4, SAS Institute, Inc, Cary, NC, USA, 2002-2012).

\section{Findings}

Overall, 1550 midwives responded to the questionnaire, but 54 were ineligible for the study (27 midwives in private practice without access to an equipped facility and 27 midwives who qualified only in 2014). These 1496 midwives practiced in 377 maternity units. The participation rate in this study was $30.5 \%$ (denominator calculated from the annual national statistics for French healthcare facilities: SAE-https://www.sae-diffusion.sante.gouv.fr/). Table 1 summarizes the respondents' characteristics. They had been in practice for a mean of $9.7 \pm 8.1$ years: $38.9 \%$ for 5 years or less, $40.7 \%$ for 6 to 15 years, and $20.4 \%$ for more than 15 ( $p=0.04)$. The largest percentage of respondents worked in level II maternity wards $(44.5 \%$ vs. $31 \%$ level III and $24.5 \%$ level I, $p=0.04)$. 
Table 1 - Characteristics of responding midwives, globally, by maternity unit levels, and by midwives' experience

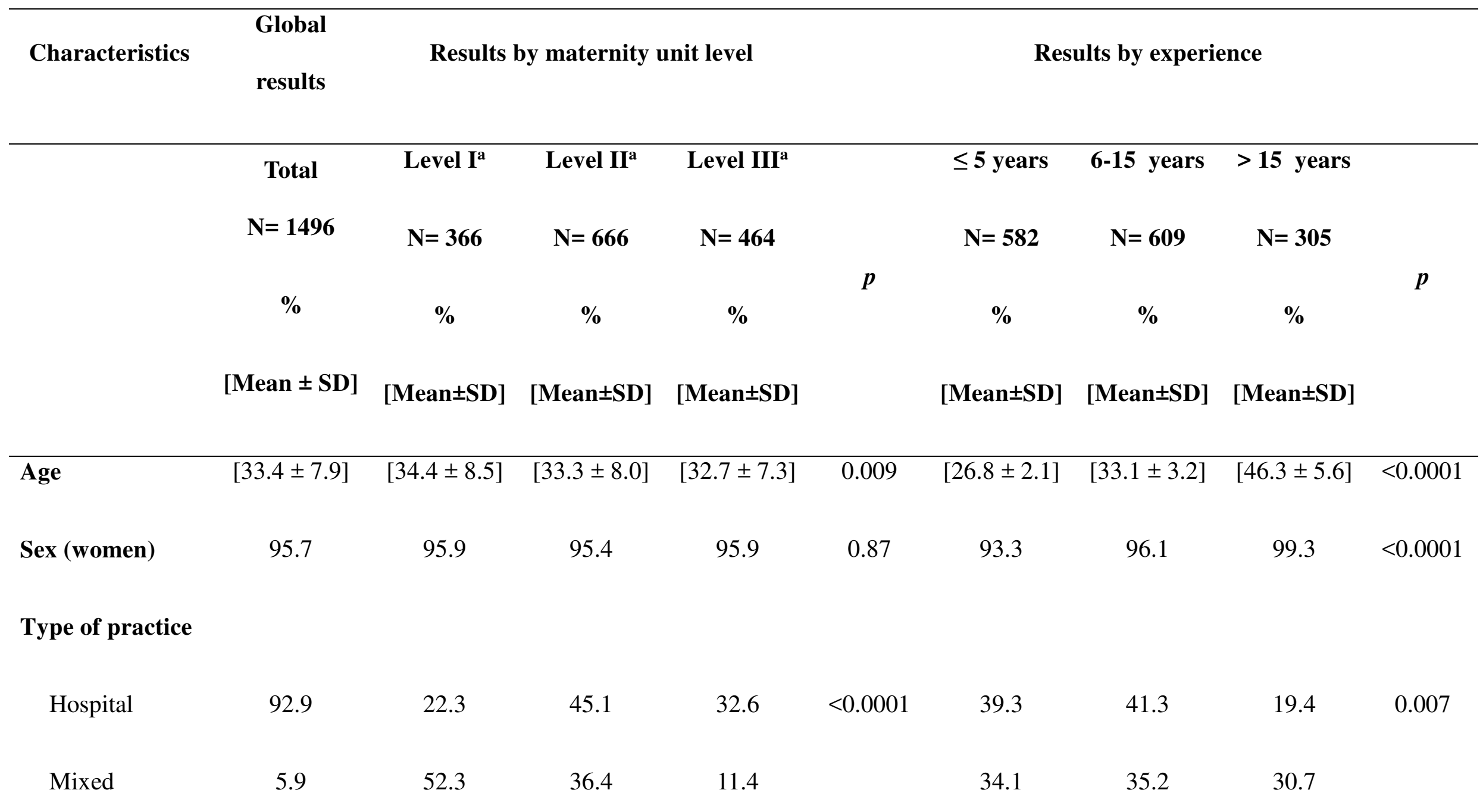


Private-

practice

13

52.6

42.1

5.3

31.6

21.1

47.4

\section{Status}

\begin{tabular}{|c|c|c|c|c|c|c|c|c|}
\hline Public & 84.2 & 19.0 & 44.2 & 36.9 & $<0.0001$ & 38.3 & 41.9 & 19.9 \\
\hline Private & 12.4 & 51.9 & 48.1 & 0 & & 43.2 & 31.9 & 24.9 \\
\hline Other & 3.5 & 59.6 & 40.4 & 0 & & 38.5 & 44.2 & 17.3 \\
\hline
\end{tabular}

\section{Deliveries/year}

$\begin{array}{lrrrrrrrrr}<500 & 35.6 & 32.8 & 41.3 & 25.9 & <0.0001 & 37.5 & 40.7 & 21.8 & <0.0001 \\ & & & & & & & & \\ & \geq 500-\leq 1500 & 23.6 & 47.3 & 51.6 & 1.1 & & 35.4 & 40.5 & 24.1 \\ >1500 & 40.8 & 3.9 & 43.3 & 52.8 & 42.1 & 40.8 & 17.1\end{array}$

${ }^{\mathrm{a}}$ Level I = maternity ward without a neonatology department; Level II = maternity ward with a neonatology department; Level III = maternity unit with a neonatology department and a neonatal intensive care unit (NICU). 


\section{Birth position}

Most midwives reported that they proposed horizontal positions during the active pushing phase: supine with footholds (79.8\%), lithotomy (80.0\%), lithotomy with knees turned in (86.7\%), and lateral one (90\%) (Table 2). Positions other than supine were proposed more often by midwives in level I units than those in level II or III facilities $(p<0.0001)$ (Table 2$)$. Midwives with $\leq 5$ years of experience proposed the lithotomy position and the supine position with footholds more often than the other midwives (respectively, $p<0.0001$ and $\mathrm{p}=0.0002$ ) (Table 2). Those with more than 15 years of experience, on the other hand, proposed the lateral position significantly less often than the others $(p<0.009)$. Midwives reported that their preferred positions were lithotomy with knees turned in $(35.2 \%)$, then lithotomy (28.6\%), and next supine with footholds (23.8\%). Only $16.2 \%$ of the midwives always let the woman choose her birthing position: $21 \%$ of those in level I, compared with $16.7 \%$ in level II and $11.9 \%$ in III units $(p=0.005)$ (Table 3 ). We note that a quarter of the midwives reported that they never or rarely left the choice of birthing position to the woman (Table 3). Most midwives reported that they most often had women use footholds (56.8\%) or stirrups (66.1\%) (Table 3). Stirrup use was most frequently reported by level III midwives $(p<0.0001)$ (Table 3). Few midwives used the support bar to position women at delivery (78.3\% never or rarely). 
Table 2 - Positions proposed by midwives during the active second stage, globally, by maternity unit level and by midwives' experience.

\begin{tabular}{|c|c|c|c|c|c|c|c|c|c|}
\hline \multirow[t]{5}{*}{ Practices proposed } & $\begin{array}{l}\text { Global } \\
\text { results }\end{array}$ & \multicolumn{4}{|c|}{ Results by maternity unit level } & \multicolumn{4}{|c|}{ Results by experience } \\
\hline & Total & Level $\mathbf{I}^{\mathbf{a}}$ & Level II ${ }^{\mathbf{a}}$ & Level III ${ }^{\mathbf{a}}$ & & & & & \\
\hline & & & & & & years & years & years & \\
\hline & $n=1496$ & $\mathrm{~N}=366$ & $N=666$ & $N=464$ & $p$ & $\mathrm{n}=582$ & $n=609$ & $n=305$ & $p$ \\
\hline & $\%$ & $\%$ & $\%$ & $\%$ & & $\%$ & $\%$ & $\%$ & \\
\hline Supine with footholds & 79.8 & 79.0 & 80.2 & 79.7 & 0.90 & 83.5 & 80.1 & 71.8 & 0.0002 \\
\hline Knees-elbows & 31.7 & 39.1 & 32.3 & 25.0 & $<0.0001$ & 30.4 & 32.5 & 32.5 & 0.70 \\
\hline Sitting position & 39.5 & 48.4 & 38.9 & 33.4 & $<0.0001$ & 36.3 & 40.1 & 44.6 & 0.05 \\
\hline Kneeling position & 28.8 & 39.3 & 28.1 & 21.6 & $<0.0001$ & 26.5 & 32.0 & 26.9 & 0.07 \\
\hline
\end{tabular}




\begin{tabular}{|c|c|c|c|c|c|c|c|c|c|}
\hline Lithotomy & 81.2 & 79.2 & 80.2 & 84.3 & 0.12 & 86.3 & 76.4 & 81.3 & $<0.0001$ \\
\hline Lithotomy with knees turned in & 86.7 & 83.9 & 87.2 & 88.2 & 0.17 & 88.5 & 86.5 & 83.6 & 0.13 \\
\hline Lateral position & 90.0 & 91.8 & 91.0 & 87.1 & 0.04 & 91.2 & 91.1 & 85.3 & 0.009 \\
\hline All fours & 48.8 & 57.7 & 50.6 & 39.2 & $<0.0001$ & 47.6 & 52.7 & 43.3 & 0.02 \\
\hline
\end{tabular}

${ }^{\mathrm{a}}$ Level I = maternity ward without a neonatology department; Level II = maternity ward with a neonatology department; Level III = maternity unit with a neonatology department and a neonatal intensive care unit (NICU). 
Table 3 - Midwives' practices for positioning women at delivery, globally, by maternity unit level and by midwives' experience.

\begin{tabular}{|c|c|c|c|c|c|c|c|c|c|}
\hline \multirow[t]{2}{*}{ Practices proposed } & $\begin{array}{l}\text { Global } \\
\text { results }\end{array}$ & \multicolumn{4}{|c|}{ Results by maternity unit level } & \multicolumn{4}{|c|}{ Results by experience } \\
\hline & Total & Level Ia & Level II & Level III & & $\leq 5$ & $6-15$ & $>15$ & \\
\hline & & & & & & years & years & years & \\
\hline & $n=1496$ & $\mathrm{~N}=366$ & $N=666$ & $\mathrm{~N}=464$ & $p$ & $\mathrm{n}=\mathbf{5 8 2}$ & $n=609$ & $\mathbf{n}=305$ & $p$ \\
\hline & $\%$ & $\%$ & $\%$ & $\%$ & & $\%$ & $\%$ & $\%$ & \\
\hline
\end{tabular}

Choice of position left to the

woman

\begin{tabular}{|c|c|c|c|c|c|c|c|c|}
\hline Never or rarely & 25.1 & 21.6 & 24.9 & 28.0 & 0.005 & 28.0 & 21.5 & 26.6 \\
\hline Often or most of the time & 58.7 & 57.4 & 58.4 & 60.1 & & 57.0 & 61.3 & 56.7 \\
\hline Always & 16.2 & 21.0 & 16.7 & 11.9 & & 15.0 & 17.2 & 16.7 \\
\hline
\end{tabular}




\section{Use of footholds}

Never or rarely

Often or most of the time

Always

\section{Use of stirrups}

Never or rarely

Often or most of the time

Always

\section{Use of the support bar}

Never or rarely

38.4

38.3

56.8

56.3

4.8

5.5

26.7

34.2

28.2

18.8

$<0.0001$

25.4

66.8

66.5

63.9

66.1

60.9

64.9

72.0

6.9

9.3

7.2

4.9

7.7

5.3

9.8

78.3

73.5

80.0

79.5

0.11

77.8

78.3

79.0

0.72 
Often or most of the time

Always

$$
20.9
$$

0.8
25.4

1.1
19.1

0.9
20.0

0.4
21.7

0.5
20.9

0.8
19.7

${ }^{\mathrm{a}}$ Level I = maternity ward without a pediatrics department; Level II = maternity ward with a neonatology department; Level III = maternity unit with a neonatology department and a NICU. 


\section{Pushing methods}

Around a third of the midwives always let women choose the type of pushing, especially those with 6 to 15 years of experience and those with more than 15 years, compared with those with $\leq 5$ years (respectively, $31.5 \%$ and $29.8 \%$ vs. $21 \%, p<0.0001$ ) (Table 4 ). Valsalva pushing was advised most often by midwives (46.4\%), especially those with $\leq 5$ years of experience (59.1\%) and those in level III units (51.1\%) (Table 4). Nearly all midwives encouraged women during their efforts $(94.7 \%)$, especially those with $\leq 5$ years of experience $(96.9 \%, p=0.0006)($ Table 4$)$. We found a mean maximum pushing time of $35.3 \mathrm{~min}( \pm 12.8$ min), longer for level-I midwives (36.9 $\min \pm 12.5, p<0.0001)$ (Figure 1). Midwives with $\leq 5$ years of experience reported a mean duration of active pushing shorter than the others $(34.2$ $\min \pm 9.2, p=0.02)($ Figure 2). 
Table 4 - Practices proposed by midwives for pushing, globally, by maternity unit level and by midwives' experience.

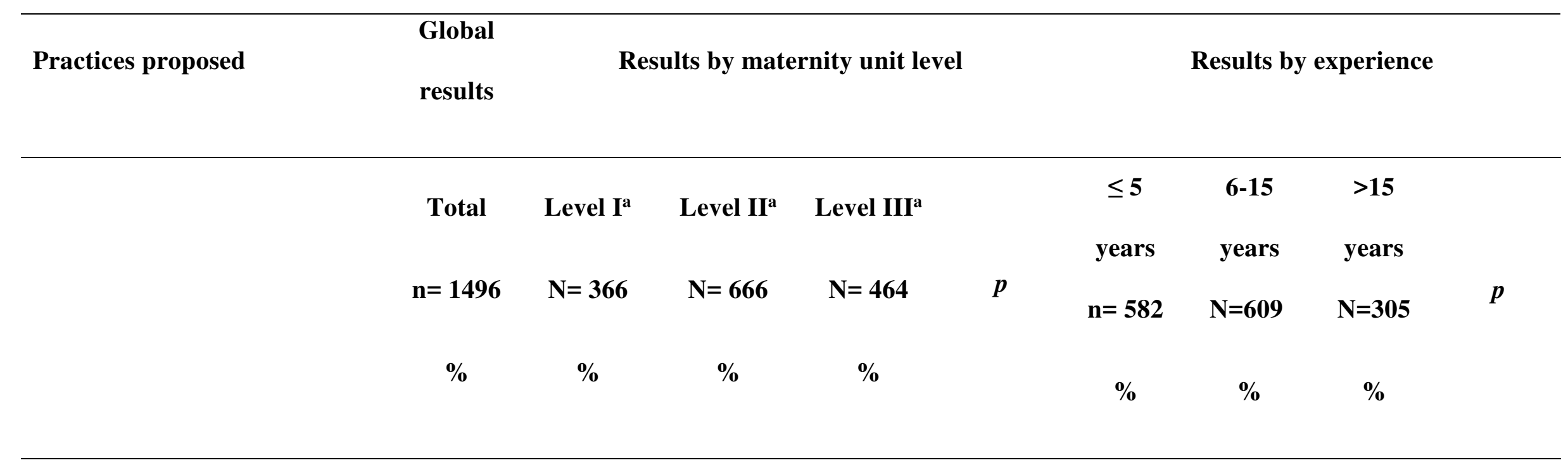

\section{Choice about type of pushing}

left to woman

\begin{tabular}{|c|c|c|c|c|c|c|c|c|}
\hline Never or rarely & 14.6 & 13.1 & 15.3 & 14.9 & 0.34 & 18.2 & 13.6 & 9.8 \\
\hline Often or most of the time & 58.3 & 56.3 & 57.7 & 60.8 & & 60.8 & 54.8 & 60.3 \\
\hline Always & 27.1 & 30.6 & 27.0 & 24.4 & & 21.0 & 31.5 & 29.8 \\
\hline
\end{tabular}




\section{Type of pushing advised}

\begin{tabular}{|c|c|c|c|c|c|c|c|c|c|}
\hline Valsalva pushing ${ }^{\mathrm{b}}$ & 46.4 & 41.5 & 45.8 & 51.1 & 0.006 & 59.1 & 42.0 & 30.8 & $<0.0001$ \\
\hline Open-glottis pushing & 25.1 & 31.4 & 25.1 & 20.3 & & 15.6 & 27.6 & 38.4 & \\
\hline Both types & 28.5 & 27.1 & 29.1 & 28.7 & & 25.3 & 30.4 & 30.8 & \\
\hline Supportive approach & 94.7 & 92.9 & 95.1 & 95.7 & 0.18 & 96.9 & 94.6 & 90.8 & 0.0006 \\
\hline Spontaneous pushing & 75.0 & 80.9 & 77.8 & 66.4 & $<0.0001$ & 76.3 & 74.1 & 74.4 & 0.65 \\
\hline
\end{tabular}




\section{Perineal techniques}

Half of the midwives reported they did not provide perineal massage during delivery $(53.5 \%)$, while one third $(31.8 \%)$ of those with $\leq 5$ years of experience did, on both the cutaneous and vaginal sides ( $p=0.0005)$ (Table 5). One quarter of the midwives reported using warm compresses on the perineum at delivery; this was significantly more frequent among those in level I units $(33.6 \%, p<0.0001)$ (Table 5). Most midwives preferred the hands-on technique at delivery $(91.4 \%)$, especially those in level III units $(95.3 \%, p=0.0006)$ and those with $\leq 5$ years of experience $(95.5 \%, p<0.0001)$ (Table 5). Most midwives used Ritgen's maneuver rarely or never (78.3\%) (Table 5). It was performed often or most of the time by $25.7 \%$ of level-III midwives $(p=0.01$ ) and $25.9 \%$ of the midwives with more than 15 years of experience $(p=0.04)$ (Table 5). At restitution, the most frequent practice was external rotation of the fetal head (54.4\%); exaggerated restitution was reported significantly more often by level-III midwives $(p=0.001)$ and those with $\leq 5$ years of experience $(p=0.002)$ (Table 5$)$. 
Table 5 - Midwives' practices for perineal protection and techniques of perineal support, globally, by maternity unit level and by midwives' experience.

\begin{tabular}{|c|c|c|c|c|c|c|c|c|c|}
\hline \multirow[t]{5}{*}{ Practices proposed } & Global & \multicolumn{4}{|c|}{ Results by maternity unit level } & \multicolumn{4}{|c|}{ Results by experience } \\
\hline & Total & Level I ${ }^{\mathbf{a}}$ & Level II ${ }^{\mathbf{a}}$ & Level III ${ }^{\mathrm{a}}$ & & & 6-15 & $>15$ & \\
\hline & & & & & & years & years & years & \\
\hline & $n=1496$ & $\mathrm{~N}=366$ & $N=666$ & $N=464$ & $p$ & $n=582$ & $n=609$ & $n=305$ & $p$ \\
\hline & $\%$ & $\%$ & $\%$ & $\%$ & & $\%$ & $\%$ & $\%$ & \\
\hline \multicolumn{10}{|l|}{ Perineal massage } \\
\hline No & 53.5 & 51.9 & 52.3 & 56.7 & 0.13 & 48.8 & 58.6 & 52.4 & 0.0005 \\
\hline Yes, cutaneous side & 7.1 & 8.2 & 8.0 & 5.0 & & 8.1 & 6.1 & 7.2 & \\
\hline Yes, vaginal side & 7.3 & 5.7 & 8.4 & 6.9 & & 6.0 & 6.6 & 11.2 & \\
\hline
\end{tabular}




$\begin{array}{lccccccc}\text { Both } & 26.1 & 27.9 & 24.5 & 27.2 & 31.8 & 22.8 & 22.0 \\ \text { Other } & 6.0 & 6.3 & 6.9 & 4.3 & 5.3 & 5.9 & 7.2\end{array}$

Lubricant (petroleum jelly, soap...)

Warm compresses

$33.6 \quad 21.8$

19.6

$<0.0001$

26.3

24.8

18.0

0.02

Management of fetal head

Hands off

Hands on

Other

Ritgen's maneuver
91.

3.3

3.6

4.5

1.5

90.5
0.0006

1.6

6.4

10.2

$<0.0001$

88.0

95.3

95.5

91.0

84.3

2.9

2.6

5.6 
Never or rarely

Often or most of the time

Always

\section{Restitution}

Spontaneous restitution

External rotation

Exaggerated restitution

Other
20.6

18.6

25.9

0.7

0.7

1.6

\section{Delivery of the head}

2.1

3.6

1.8

1.5

30.3

54.4

56.6

55.1

51.7

53.4

13.2

7.1

14.1

16.6

16.5

12.6

7.9

1.6

2.6

2.3

0.04 


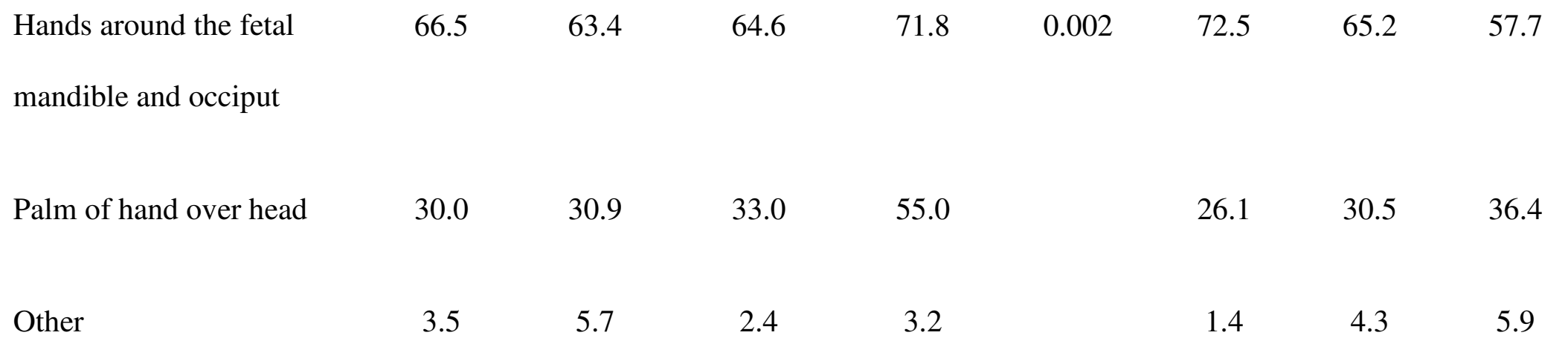

${ }^{\mathrm{a}}$ Level I = maternity ward without a neonatology department; Level II = maternity ward with a neonatology department; Level III = maternity unit with a neonatology department and a neonatal intensive care unit (NICU). 


\section{Third stage of labor}

For placental delivery, $75.9 \%$ of the midwives said that they changed the woman's initial position; this was more frequent among the youngest midwives $(\leq 5$ years of experience and between 6 and 15; respectively, 80.9\% and 76.8\%) than those with more than 15 years of experience $(64.3 \%, p<0.0001)$. This practice did not differ by maternity ward level. Among those who reported a change in the mother's position, $97.1 \%$ recommended a supine position for this phase, especially those in level III units $(98.6 \%, p=0.03)$.

\section{Facilitating physiological childbirth}

Among the respondents, $81.9 \%$ of the midwives thought that their labor management often or always ensured physiological childbirth. Three quarters of the midwives (76.7\%) working in level III units thought so, versus $82.8 \%$ of those in level II units and $86.9 \%$ of those in level I ( $p=0.0006)$. Overall, only $38.2 \%$ of midwives were comfortable with all the maternal positions for fetal expulsion: $48.4 \%$ in level I units compared with $38.0 \%$ in level II and $30.4 \%$ in level III units $(p<0.0001)$. It was also the case for $43 \%$ of the midwives with more than 15 years of experience versus $40.4 \%$ of those with 6 to 15 years of experience and $33.3 \%$ of those with $\leq 5$ years $(p=0.007)$.

\section{Discussion}

This large cross-sectional study enables us to describe the practices of French midwives, until now little documented, especially for physiological births. Although epidemiologic studies describe these deliveries, their outcomes, and the women's characteristics (Blondel and Kermarrec, 2011; Audipog), few French studies have focused on midwives' practices. A recent French study conducted in different maternity units and covering only 551 women with 
spontaneous vaginal deliveries found practices similar to ours, with $86.1 \%$ of deliveries in supine (or lithotomy) positions, $3.8 \%$ in lateral positions, $0.9 \%$ on hands and knees, and $1 \%$ upright positions (Desseauve et al., 2016). In our study, $87.6 \%$ of midwives reported that they prefer dorsal positions, whether supine with footholds or lithotomy with knees turned in or not. Regular use of stirrups was also reported by $66 \%$ of midwives. A Canadian survey in 2006 also found stirrup use in 57\% of deliveries (Chalmers et al., 2012). Although stirrup use does not appear to be associated with an increase in perineal tears or lacerations (Corton et al., 2012), other studies have found that the lithotomy position is a risk factor for OASIS, especially in parous women (Elvander et al., 2015). Moreover, stirrup use constrains the woman to maintain the same supine position through her active pushing, which can have a harmful effect on fetal oxygenation (Carbonne et al., 1996). The National Institute for Health and Care Excellence (NICE) recommends that British physicians discourage women woman from lying in supine or semi-supine positions during the second stage of labor (NICE, 2017). Nonetheless, the study on birthing positions published by the Royal College of Midwives found that $51 \%$ of the women who gave birth normally used a semi-supine position, and only 3\% the lithotomy position (RCM, 2010). A Swedish study found a lower percentage of lithotomy positions at delivery, with the rate varying by parity (nulliparous $\sim 25 \%$, parous 10\%) (Elvander et al., 2015). In the same study, sitting was the position used most often by both nulliparous (38.5\%) and parous (41.3\%) women (Elvander et al., 2015). A Dutch study, on the other hand, found supine positions in $89.7 \%$ of deliveries in 2005 , both in hospital and at home (de Jonge et al., 2009). These authors observed different social and demographic factors associated with the use of a non-supine position, including the mother's age ( $\geq 36$ years), a higher education level, and homebirth.

In France, during the second stage, "delayed pushing" is the standard clinical practice. The French National College of Gynecologists-Obstetricians (CNGOF) recommends delayed 
pushing ( $2 \mathrm{~h}$ after dilation) for women with epidural analgesia, to reduce the number of difficult operative vaginal deliveries (Vayssière et al., 2011). There are, however, currently no guidelines about the type of pushing to be used. In our study, $46.4 \%$ of midwives advised closed-glottis pushing, also known as Valsalva pushing (Barasinski et al., 2016). We found very few studies describing techniques used by midwives across the globe. A cross-sectional Japanese study found that Valsalva pushing was used in almost all cases by $37.9 \%$ of hospitals, $50 \%$ of clinics, and only $10 \%$ of midwifery birth centers (Baba et al., 2016). An American study found that $25.7 \%$ of women having a first vaginal birth and $16.3 \%$ of parous women who participated in a randomized clinical trial of perineal management techniques used Valsalva pushing (Albers et al., 2006). Another American study found more directive approaches when women have an epidural (Osborne and Hanson, 2012). According to the Royal College of Midwives, there is no good evidence to justify the use of directed pushing with Valsalva breathing, and indeed the practice of sustained breath holding in directed pushing may be harmful (RCM, 2012).

The mean maximum duration of pushing in our study was 35.3 minutes. In France, the CNGOF guidelines recommend operative vaginal delivery when the pushing stage exceeds 30 minutes, subject to no anomalies in the fetal heart rate (Dupuis and Simon, 2008). Nonetheless, this policy is not followed internationally (Le Ray and Audibert, 2008), and durations of active pushing can exceed 4 hours (Grobman et al., 2016).

Looking at perineal protection techniques, the US study by Albers et al. (2006) found that $34.5 \%$ of women with first vaginal births and $31.9 \%$ of parous women had warm compresses at delivery, and an Australian survey found that $44.9 \%$ of the midwives questioned used these compresses (East et al., 2015). Only $24 \%$ of the midwives in our study reported using them at delivery. Our survey showed widespread use of the hands-on technique $(91.4 \%$ of respondents), although it too appears to be used much less frequently internationally: in 
Australia, between $37 \%$ and $60.9 \%$ of midwives use it, depending on the study (Ampt et al., 2015; East et al., 2015) and in England, 48.6\% (Trochez et al., 2011). The contradictory data in the literature about manual perineal support (Bulchandani et al., 2015) is mirrored by the different attitudes professionals have towards this practice. Nonetheless, this common practice in France is associated with a lower rate of severe perineal lacerations $\left(3^{\text {rd }}\right.$ and $4^{\text {rd }}$ degree $)$ ( $0.54 \%$ in 2012, Audipog) than in other countries not using this practice (Sweden between 4.2\% and 5.7\%, Denmark 3.6\%, Norway 4.1\%, England 3.1\%) (Ekéus et al., 2008; Birthplace in England Collaborative Group, 2011; Laine et al., 2009).

Our study shows that practices differ among midwives as a function of their experience but also of their place of work, as previously reported in the literature (Wiklund et al., 2012; Zinsser et al., 2016). Different authors have observed more physiological practices in out-ofhospital birth centers (Zinsser et al., 2016; Baba et al., 2016). The Birthplace study found that its large cohort of women planning birth in a midwifery unit and multiparous women planning birth at home experienced fewer interventions than those planning birth in an obstetric unit (Birthplace in England Collaborative Group, 2011). French midwives working in level I units, where only women with low-risk pregnancies can give birth, considered that physiological childbirth took place more often than those in level II and III facilities. We found that these midwives used more varied practices with more non-recumbent birth positions, more openglottis pushing, more spontaneous pushing, and more perineal application of warm compresses. Nonetheless, another study failed to find any difference in the observed rate of interventions (induction of labor, cesarean section, operative vaginal delivery, and episiotomy) in France according to hospital level. Instead, it found that intervention rates appear to depend on maternity unit status - public or private (Coulm et al., 2012). Nonetheless, the practices they examined were not, as those in our study were, specific to midwifery; indeed, theirs were more specific to obstetricians. Some countries have analyzed 
their optimality of their practices according to current evidence to identify the optimal processes of care and the clinical outcomes achieved in relation to background risk factors (Sheridan and Sandall, 2010). Developed by Wiegers et al. (1996), the "Optimality Index" seems to be a useful approach to studies involving midwifery care (American College of Nurse-Midwives, 2016). It would be interesting to use this process in France by adapting this tool, or to develop an international tool for the comparison of background risk and outcomes across a range of care settings (Sheridan and Sandall, 2010).

\section{Strengths and Limitations}

Our low participation rate (30.5\%) (Eysenbach, 2004) was nonetheless an underestimate because the exact number of midwives participating in deliveries in each maternity ward in France is unavailable. We used the national database of healthcare facility statistics (SAE), which reports the number of midwives practicing in maternity units, regardless of their actual work in those units. Some midwives, however, no longer work in the delivery room (eg, they may do prenatal and postnatal care, or administration), which artificially diminishes our participation rate. Our participation rate is nonetheless good for a survey of practices among the general population of midwives, since response rates in other general population-based studies have been less than 15\% (Arrish et al., 2016; George et al., 2016; RCM, 2010). We could not define a target sample to determine a representative sample of the population of French midwives involved in the delivery of babies because there is no national register of all French midwives that includes their professional characteristics. Moreover, French midwives are not required to join the French National College of French Midwives (CNSF). Another weakness of our study is its reliance on midwives' self-report. That is, professionals do not always do what they say they do. In 2013 France had 519 maternity units (DRESS); accordingly, respondents reported practices in $72.7 \%$ of French public and private maternity units. 
In conclusion, the practices reported by French midwives are not always consistent with the scientific literature or with a physiological approach to birth. These practices vary as a function of the midwife's experience and the level of the maternity ward where she works. The absence of professional guidelines for midwives in France surely plays a role in this finding, especially since the scientific literature is written almost exclusively in English which is not read by most of the French midwives. Moreover, although research in midwifery is highly developed in some countries (Luyben et al., 2013), it is only just beginning in France. Thus, in 2010, only 10 midwives in France had a PhD. Studies of midwifery care have recently begun to appear (Le Ray et al., 2016; Barasinski and Vendittelli, 2016), however, and are the beginning of the development of a culture of research and the appropriation of evidence-based midwifery by French midwives. A better description of midwives' practices in all countries will help us to understand how they affect the health of women and newborns by comparing national maternal and neonatal indicators. This study is useful to the development of a qualitative research project that would allow us to identify the obstacles to and facilitating factors for the appropriation of international evidence-based practices by French midwives.

\section{References}

Aasheim, V., Nilsen, A.B.V., Lukasse, M., Reinar, L.M., 2011. Perineal techniques during the second stage of labour for reducing perineal trauma, in: The Cochrane Collaboration (Ed.), Cochrane Database of Systematic Reviews. John Wiley \& Sons, Ltd, Chichester, UK. doi:10.1002/14651858.CD006672.pub2

Albers, L.L., Sedler, K.D., Bedrick, E.J., Teaf, D., Peralta, P., 2006. Factors Related to Genital Tract Trauma in Normal Spontaneous Vaginal Births. Birth 33, 94-100. doi:10.1111/j.0730-7659.2006.00085.x 
Ampt, A.J., de Vroome, M., Ford, J.B., 2015. Perineal management techniques among midwives at five hospitals in New South Wales - A cross-sectional survey. Australian and New Zealand Journal of Obstetrics and Gynaecology 55, 251-256. doi:10.1111/ajo.12330

Arrish, J., Yeatman, H., Williamson, M., 2016. Australian midwives and provision of nutrition education during pregnancy: A cross sectional survey of nutrition knowledge, attitudes, and confidence. Women and Birth. doi:10.1016/j.wombi.2016.03.001

Baba, K., Kataoka, Y., Nakayama, K., Yaju, Y., Horiuchi, S., Eto, H., 2016. A cross-sectional survey of policies guiding second stage labor in urban Japanese hospitals, clinics and midwifery birth centers. BMC Pregnancy and Childbirth 16. doi:10.1186/s12884-016-0814-2 Barasinski, C., Lemery, D., Vendittelli, F., 2016. Do maternal pushing techniques during labour affect obstetric or neonatal outcomes? Gynécologie Obstétrique \& Fertilité 44, 578583. doi:10.1016/j.gyobfe.2016.07.004

Barasinski, C., Vendittelli, F., 2016. Effect of the type of maternal pushing during the second stage of labour on obstetric and neonatal outcome: a multicentre randomised trial— the EOLE study protocol. BMJ Open 6, e012290. doi:10.1136/bmjopen-2016-012290

Birthplace in England Collaborative Group, 2011. Perinatal and maternal outcomes by planned place of birth for healthy women with low risk pregnancies: the Birthplace in England national prospective cohort study. BMJ 343, d7400-d7400. doi:10.1136/bmj.d7400

Bulchandani, S., Watts, E., Sucharitha, A., Yates, D., Ismail, K., 2015. Manual perineal support at the time of childbirth: a systematic review and meta-analysis. BJOG: An International Journal of Obstetrics \& Gynaecology 122, 1157-1165. doi:10.1111/14710528.13431 
Carbonne, B., Benachi, A., Leveque, M., Cabrol, D., Papiernik, E., 1996. Maternal position during labor: effects on fetal oxygen saturation measured by pulse oximetry. Obstetrics \& Gynecology 88, 797-800. doi:10.1016/0029-7844(96)00298-0

Chalmers, B., Kaczorowski, J., O‘Brien, B., Royle, C., 2012. Rates of Interventions in Labor and Birth across Canada: Findings of the Canadian Maternity Experiences Survey. Birth 39, 203-210. doi:10.1111/j.1523-536X.2012.00549.x

Coulm, B., Ray, C., Lelong, N., Drewniak, N., Zeitlin, J., Blondel, B., 2012. Obstetric Interventions for Low-Risk Pregnant Women in France: Do Maternity Unit Characteristics Make a Difference? Birth 39, 183-191. doi:10.1111/j.1523-536X.2012.00547.x

Corton, M.M., Lankford, J.C., Ames, R., McIntire, D.D., Alexander, J.M., Leveno, K.J., 2012. A randomized trial of birthing with and without stirrups. American Journal of Obstetrics and Gynecology 207, 133.e1-133.e5. doi:10.1016/j.ajog.2012.06.043

De Jonge, A., Van Diem, Mt., Scheepers, P., Van Der Pal-de Bruin, K., Lagro-Janssen, A., 2007. Increased blood loss in upright birthing positions originates from perineal damage. BJOG: An International Journal of Obstetrics \& Gynaecology 114, 349-355. doi:10.1111/j.1471-0528.2006.01210.x

de Jonge, A., Rijnders, M.E.B., van Diem, M.T., Scheepers, P.L.H., Lagro-Janssen, A.L.M., 2009. Are there inequalities in choice of birthing position? Midwifery 25, 439-448. doi:10.1016/j.midw.2007.07.013

Desseauve, D., Gachon, B., Bertherat, P., Fradet, L., Lacouture, P., Pierre, F., 2016. Dans quelle position les femmes accouchent-elles en 2015 ? Résultats d'une étude prospective régionale multicentrique. Gynécologie Obstétrique \& Fertilité 44, 548-556. doi:10.1016/j.gyobfe.2016.06.010 
Dupont, C., Carayol, M., Le Ray, C., Deneux-Tharaux, C., Riethmuller, D., 2017. Oxytocin administration during spontaneous labor: Guidelines for clinical practice. Guidelines short text. Journal of Gynecology Obstetrics and Human Reproduction.

doi:10.1016/j.jogoh.2017.04.010

Dupuis, O., Simon, A., 2008. La surveillance fotale pendant l'expulsion. Journal de Gynécologie Obstétrique et Biologie de la Reproduction, 37, S93-S100. doi:10.1016/j.jgyn.2007.11.015

East, C.E., Lau, R., Biro, M.A., 2015. Midwives' and doctors' perceptions of their preparation for and practice in managing the perineum in the second stage of labour: a cross-sectional survey. Midwifery 31, 122-131. doi:10.1016/j.midw.2014.07.002

Ekéus, C., Nilsson, E., Gottvall, K., 2008. Increasing incidence of anal sphincter tears among primiparas in Sweden: A population-based register study. Acta Obstetricia et Gynecologica Scandinavica 87, 564-573. doi:10.1080/00016340802030629

Elvander, C., Ahlberg, M., Thies-Lagergren, L., Cnattingius, S., Stephansson, O., 2015. Birth position and obstetric anal sphincter injury: a population-based study of 113000 spontaneous births. BMC Pregnancy and Childbirth 15. doi:10.1186/s12884-015-0689-7

Eysenbach, G., 2004. Improving the Quality of Web Surveys: The Checklist for Reporting Results of Internet E-Surveys (CHERRIES). Journal of Medical Internet Research. doi:10.2196/jmir.6.3.e34

George, A., Dahlen, H.G., Blinkhorn, A., Ajwani, S., Bhole, S., Ellis, S., Yeo, A., Elcombe, E., Sadozai, A., Johnson, M., 2016. Measuring oral health during pregnancy: sensitivity and specificity of a maternal oral screening (MOS) tool. BMC Pregnancy and Childbirth. doi:10.1186/s12884-016-1140-4 
Grobman, W.A., Bailit, J., Lai, Y., Reddy, U.M., Wapner, R.J., Varner, M.W., Caritis, S.N., Prasad, M., Tita, A.T.N., Saade, G., Sorokin, Y., Rouse, D.J., Blackwell, S.C., Tolosa, J.E., Eunice Kennedy Shriver National Institute of Child Health and Human Development (NICHD) Maternal-Fetal Medicine Units (MFMU) Network, 2016. Association of the Duration of Active Pushing With Obstetric Outcomes. Obstet Gynecol 127, 667-673. doi:10.1097/AOG.0000000000001354

Gupta, J.K., Hofmeyr, G.J., Shehmar, M., 2012. Position in the second stage of labour for women without epidural anaesthesia, in: The Cochrane Collaboration (Ed.), Cochrane Database of Systematic Reviews. John Wiley \& Sons, Ltd, Chichester, UK. doi:10.1002/14651858.CD002006.pub3

Hals, E., Øian, P. al, Pirhonen, T., Gissler, M., Hjelle, S., Nilsen, E.B., Severinsen, A.M., Solsletten, C., Hartgill, T., Pirhonen, J., 2010. A multicenter interventional program to reduce the incidence of anal sphincter tears. Obstetrics \& Gynecology 116, 901-908.

Hanson, L., 1998. PRACTICES: Part 1: Position Use and Preferences. Journal of NurseMidwifery 43, 320-325. doi:10.1016/S0091-2182(98)00033-0

Ismail, K.M.K., Paschetta, E., Papoutsis, D., Freeman, R.M., 2015. Perineal support and risk of obstetric anal sphincter injuries: a Delphi survey. Acta Obstet Gynecol Scand 94, 165-174. doi:10.1111/aogs.12547

Kibuka, M., Thornton, J.G., 2017. Position in the second stage of labour for women with epidural anaesthesia, in: The Cochrane Collaboration (Ed.), Cochrane Database of Systematic Reviews. John Wiley \& Sons, Ltd, Chichester, UK. doi:10.1002/14651858.CD008070.pub3 
Laine, K., Gissler, M., Pirhonen, J., 2009. Changing incidence of anal sphincter tears in four Nordic countries through the last decades. European Journal of Obstetrics \& Gynecology and Reproductive Biology 146, 71-75. doi:10.1016/j.ejogrb.2009.04.033

Laine, K., Skjeldestad, F.E., Sandvik, L., Staff, A.C., 2012. Incidence of obstetric anal sphincter injuries after training to protect the perineum: cohort study. BMJ Open 2, e001649. doi:10.1136/bmjopen-2012-001649

Lemos, A., Amorim, M.M., Dornelas de Andrade, A., de Souza, A.I., Cabral Filho, J.E., Correia, J.B., 2017. Pushing/bearing down methods for the second stage of labour, in: The Cochrane Collaboration (Ed.), Cochrane Database of Systematic Reviews. John Wiley \& Sons, Ltd, Chichester, UK. doi:10.1002/14651858.CD009124.pub3

Le Ray, C., Audibert, F., 2008. Durée des efforts expulsifs : données de la littérature. Journal de Gynécologie Obstétrique et Biologie de la Reproduction 37, 325-328. doi:10.1016/j.jgyn.2008.02.009

Le Ray, C., Lepleux, F., De La Calle, A., Guerin, J., Sellam, N., Dreyfus, M., Chantry, A.A., 2016. Lateral asymmetric decubitus position for the rotation of occipito-posterior positions: multicenter randomized controlled trial EVADELA. Am. J. Obstet. Gynecol. 215, 511.e1-7. doi:10.1016/j.ajog.2016.05.033

Luyben, A.G., Wijnen, H.A.A., Oblasser, C., Perrenoud, P., Gross, M.M., 2013. The current state of midwifery and development of midwifery research in four European countries. Midwifery 29, 417-424. doi:10.1016/j.midw.2012.10.008

Osborne, K., Hanson, L., 2012. Directive Versus Supportive Approaches Used by Midwives When Providing Care During the Second Stage of Labor. Journal of Midwifery \& Women's Health 57, 3-11. doi:10.1111/j.1542-2011.2011.00074.x 
Royal College of Midwives (RCM), 2010 .The Royal College of Midwives' Survey of positions used in labour and birth. London : RCM.

Sheridan, M., Sandall, J., 2010. Measuring the best outcome for the least intervention: can the Optimality Index-US be applied in the UK? Midwifery 26, e9-e15.

doi:10.1016/j.midw.2009.09.002

Soong, B., Barnes, M., 2005. Maternal Position at Midwife-Attended Birth and Perineal Trauma: Is There an Association? Birth 32, 164-169.

Trochez, R., Waterfield, M., Freeman, R.M., 2011. Hands on or hands off the perineum: a survey of care of the perineum in labour (HOOPS). Int Urogynecol J 22, 1279-1285. doi:10.1007/s00192-011-1454-8

Vayssière, C., Beucher, G., Dupuis, O., Feraud, O., Simon-Toulza, C., Sentilhes, L., Meunier, E., Parant, O., Schmitz, T., Riethmuller, D., Baud, O., Galley-Raulin, F., Diemunsch, P., Pierre, F., Schaal, J.-P., Fournié, A., Oury, J.F., French College of Gynaecologists and Obstetricians, 2011. Instrumental delivery: clinical practice guidelines from the French College of Gynaecologists and Obstetricians. Eur. J. Obstet. Gynecol. Reprod. Biol. 159, 4348. doi:10.1016/j.ejogrb.2011.06.043

Vendittelli, F., 2012. Le type de poussée et la position maternelle pendant le 2e stade du travail ont-ils un impact sur les issues obstétricales ou néonatales? In : Dreyfus, M., d'Ercole, C., 42es journées nationales de la Société Française de Médicine Périnatale. Springer, France. pp. 135-153.

Wiegers, T.A., Keirse, M., Berghs, G.A.H., Van der Zee, J., 1996. An approach to measuring quality of midwifery care. Journal of clinical epidemiology 49, 319-325. 
Wiklund, I., Wallin, J., Vikström, M., Ransjö-Arvidson, A.-B., 2012. Swedish midwives' rating of risks during labour progress and their attitudes toward performing intrapartum interventions: a web-based survey. Midwifery 28, e516-e520.

doi:10.1016/j.midw.2011.06.008

Zinsser, L.A., Stoll, K., Gross, M.M., 2016. Midwives' attitudes towards supporting normal labour and birth - A cross-sectional study in South Germany. Midwifery 39, 98-102. doi:10.1016/j.midw.2016.05.006

\section{Web references}

American College of Nurse-Midwives, 2016. Measuring Outcomes of Midwifery Care: The Optimality Index-US http://www.midwife.org/Optimality-Index-US

Audipog-Association des Utilisateurs de Dossiers Informatisés en Pédiatrie, Obstétrique et Gynécologie, http://www.audipog.net/interro-choix.php?langue=en

Bellamy V., Beaumel C., 2016. Bilan démographique 2015 : le nombre de décès au plus haut depuis l'après-guerre. Insee Première. https://www.insee.fr/fr/statistiques/1908103

Blondel B., Kermarrec M., 2011. Les naissances en 2010 et leur évolution depuis 2003. In Enquête nationale périnatale 2010. Institut national de la santé et de la recherche médicale, Ministère du travail de l'emploi et de la Santé, Paris. http://socialsante.gouv.fr/IMG/pdf/Les_naissances_en_2010_et_leur_evolution_depuis_2003.pdf

Cour des comptes, 2014. Les maternités cahier 1 : analyse générale. https://www.ccomptes.fr/sites/default/files/EzPublish/20150123-rapport-les-maternitespremier-cahier.pdf 
Direction de la Recherche, des études et de l'évaluation et des statistiques (DRESS), http://www.data.drees.sante.gouv.fr/

Institut national de la statistique et des études économiques (INSEE), 2014. Les naissances en 2013 - Tableaux France. https://www.insee.fr/fr/statistiques/2046467? sommaire=2106233

National Institute for Health and Care Excellence, 2017. Intrapartum care for healthy women and babies. https://www.nice.org.uk/guidance/cg190/resources/intrapartum-care-for-healthywomen-and-babies-35109866447557

Statistique Annuelle des Etablissements de santé (SAE), https://www.saediffusion.sante.gouv.fr/

The Royal College of Midwives, 2012. Evidence based guidelines for midwifery-led care in labour - Second stage of labour.

https://www.rcm.org.uk/sites/default/files/Second\%20Stage\%20of\%20Labour.pdf 